\title{
Detection Principles of Temperature Compensated Oscillators with Reactance Influence on Piezoelectric Resonator
}

\author{
Vojko Matko *(D) and Miro Milanovič $(\mathbb{D}$ \\ Faculty of Electrical Engineering and Computer Science, University of Maribor, Koroška c. 46, 2000 Maribor, \\ Slovenia; miro.milanovic@um.si \\ * Correspondence: vojko.matko@um.si; Tel.: +386-2-220-7111
}

Received: 21 December 2019; Accepted: 30 January 2020; Published: 1 February 2020

\begin{abstract}
This review presents various ways of detection of different physical quantities based on the frequency change of oscillators using piezoelectric crystals. These are influenced by the reactance changes modifying their electrical characteristics. Reactance in series, in parallel, or a combination of reactances can impact the electrical crystal substitute model by influencing its resonant oscillation frequency. In this way, various physical quantities near resonance can be detected with great sensitivity through a small change of capacitance or inductance. A piezoelectric crystal impedance circle and the mode of frequency changing around the resonant frequency change are shown. This review also presents the influence of reactance on the piezoelectric crystal, the way in which the capacitance lost among the crystal's electrodes is compensated, and how the mode of oscillators' output frequency is converted to lower frequency range (1-100 kHz). Finally, the review also explains the temperature-frequency compensation of the crystals' characteristics in oscillators that use temperature-frequency pair of crystals and the procedure of the compensation of crystals own temperature characteristics based on the method switching between the active and reference reactance. For the latter, the experimental results of the oscillator's output frequency stability $\left(f_{\text {out }}= \pm 0.002 \mathrm{ppm}\right)$ at dynamical change of environment temperature $\left(0-50^{\circ} \mathrm{C}\right)$ are shown.
\end{abstract}

Keywords: piezoelectric impedance; reactance influence on resonance; detection principle of piezoelectric oscillators

\section{Introduction}

There are many different types of oscillators using crystals as the key components of their circuit. The quartz oscillator, in particular, is uniquely suited for the manufacture of frequency selection or frequency control devices [1-3]. On the other hand, these oscillators can be used for the detection of various physical quantities based on the frequency change that can be triggered by mechanical influence on the crystal [4] or electrical influence on its substitute electrical model [1,5]. The purpose of this study is to provide an overview of various ways of detection of physical quantities using oscillators with a piezoelectric crystal (as an oscillating element) and reactance connected in series or in parallel. The latter influences the crystal's electric substitute model and consequently its performance characteristics (the oscillating frequency near the resonance) [6-8]. The advantage of this method is great enhancement of sensor sensitivity, excellent temperature compensation, as well as compensation of capacitance among the crystal's electrodes and other parasitic impedances.

Current state of the research field: In [9], a calibration method based on self-reciprocity is proposed for the determination of transducer sensitivity, which can be applied to both planar and focused transducers. The two-port electrical network of the experimental setup is analyzed, and 
a simplified measurement procedure is described in which the "impedance mismatch" problem is solved. Another paper [10] presents an equivalent circuit model, a systematic design, and an optimization method for developing a broadband annular diaphragm piezoelectric micromachined ultrasonic transducer (A-PMUT). By utilizing array analysis methods, an annular diaphragm is regarded as an array consisting of equally spaced sector diaphragms influencing each other by crosstalk effects [11]. The model successfully explains the phenomenon of multi-resonance peaks in the frequency response curve, sharing the same vibration mode. Researchers in [12] present an initial, large-scale investigation into embedding shear-mode lead zirconate titanate piezoelectric transducers into the bond line of laminate structures, near the centerline, for the ultrasonic detection of joint defects. Simulations were performed for models containing disbonds, through-thickness cracks, and voids with experimental validation of a specimen containing a void to evaluate the effectiveness of lead zirconate titanates embedded in a bondline as sensors for damage detection. In [13], implantable middle ear hearing devices were developed as a new technology to overcome the limitations of conventional hearing aids. In this article a new piezoelectric transducer based on a piezoelectric stack is proposed and designed. This new transducer, attached to the incus body with a coupling rod, stimulates the ossicular chain in response to the expansion-and-contraction of its piezoelectric stack. In [14], the research describes the design of an amplifier for a piezoelectric transducer used in underwater communication applications. The proposed architecture combines hysteretic ripple current-mode control with an adaptive soft switching technique to achieve improved power efficiency over the full output power range. This is achieved by dynamically controlling the inductor current ripple to keep the converter running in soft switching. In [5], two piezoelectric transducers were designed to meet the strict underwater application backgrounds such as high pressure, corrosion resistance, and high strength. The two models were constructed and compared with chosen sets of geometric parameters, which can also provide a reference for low-frequency transducer design. The experimental results of proposed transducers show a good consistency, which indicates that the cavity structure can reduce the resonance frequency. In [15] a general model was developed that describes the electrical responses of thickness-shear mode resonators subject to a variety of surface conditions. The model incorporates a physically diverse set of single-component loadings, including rigid solids, viscoelastic media, and fluids (Newtonian or Maxwellian). In [16] the method improving quartz oscillator temperature-frequency characteristics compensation is switching between two impedance loads. By modifying the oscillator circuit with two logic switches and two impedance loads, the oscillator can switch oscillation between two resonance frequencies. The difference in resonance frequencies compensates the temperature-frequency characteristics' influence as well as the influence of offset and quartz crystal ageing.

This work provides an overview of ways of detection of different physical quantities using oscillators with piezoelectric crystals and load impedance connected in series or parallel through which we impact the electrical substitute crystal model and its performance characteristics. In oscillators with load capacitance or inductance in series or parallel with the crystal unit, the oscillation frequency depends on the capacitive or inductive load that is applied. The frequency will increase if the capacitive load is decreased and decrease if the load is increased. The amount of frequency change (in ppm) as a function of load capacitance is different for various ways of influencing the electrical substitute model of the piezoelectric crystal. It indicates how far from the nominal frequency (intended oscillating frequency) the resonant frequency can be forced by applying the load. In this case, it can be used for measurement purposes, allowing the measurement of various physical quantities based on capacitive and inductive influence on the quartz crystal's oscillation frequency. A huge advantage of these ways of detection of piezoelectric oscillators is a very good temperature compensation of the crystal's own temperature-frequency characteristics (although this is not always necessary in certain cases) and an improved impedance-to-frequency change sensitivity. 


\section{Piezoelectric Crystal Equivalent Circuit and its Impedance}

The operation of a piezoelectric crystal is frequently explained using the equivalent circuit, illustrated in Figure 1, representing an electrical depiction of the quartz crystal unit $[1,6,15,17,18]$. The capacitance labeled $\mathrm{C}_{0}$ is real capacitance, comprising the capacitance between the electrodes and the stray capacitance associated with the mounting structure. It is also known as the "shunt" or "static" capacitance, and represents the crystal in a non-operational state. This can also depend on the medium where the piezoelectric is located, namely conductive or non-conductive medium. The other components represent the crystal in an operational or motional state; $\mathrm{L}_{1}, \mathrm{C}_{1}$, and $\mathrm{R}_{1}$ identify the "motional inductance", the "motional capacitance", and the "motional resistance", respectively. The motional inductance $L_{1}$ represents the vibrating mass of the quartz plate, while the motional capacitance $C_{1}$ represents the elasticity or stiffness of the plate. The motional resistance $R_{1}$ represents the bulk losses occurring within the vibrating plate.

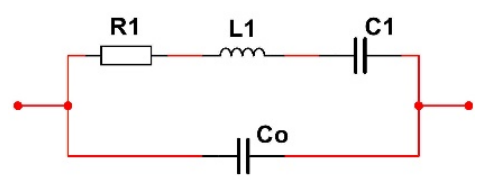

Figure 1. The piezoelectric crystal equivalent circuit (Butterworth Van-Dyke (BVD) model) [19,20].

The piezoelectric crystal has two resonance frequencies, namely the series resonance frequency $f_{\mathrm{s}}$ and the parallel resonance frequency $f_{\mathrm{p}}$. The series and parallel resonance frequencies and the quality factor $Q$ are specified by the following equations $[1,6,21]$ :

$$
\begin{gathered}
f_{s}=\frac{1}{2 \pi \cdot \sqrt{L_{1} C_{1}}} \\
f_{p}=\frac{1}{2 \pi \cdot \sqrt{L_{1} \frac{C_{1} C_{0}}{C_{1}+C_{0}}}}=f_{s} \sqrt{1+\frac{C_{1}}{C_{0}}} \\
Q=\frac{2 \pi f_{s} L_{1}}{R_{1}}=\frac{1}{2 \pi f_{s} R_{1} C_{1}}
\end{gathered}
$$

The complex impedance equation for the piezoelectric crystal equivalent circuit (Figure 1) $[1,6,21]$ is

$$
\underline{Z}=\frac{\left(R_{1}+j \omega L_{1}+\frac{1}{j \omega C_{1}}\right) \frac{1}{j \omega C_{0}}}{R_{1}+j \omega L_{1}+\frac{1}{j \omega C_{1}}+\frac{1}{j \omega C_{0}}}=\frac{R_{1}+j\left(\omega L_{1}-\frac{1}{\omega C_{1}}\right)}{1+\frac{C_{0}}{C_{1}}-\omega^{2} L_{1} C_{0}+j \omega R_{1} C_{0}}
$$

By introducing the normalized frequency $\Omega=\omega / \omega_{0}$, which is related to the resonance frequency $\omega_{0}=1 / \sqrt{L_{1} C_{1}}$, taking into account $\omega_{0} L_{1}=1 / \omega_{0} C_{1}$ and $\omega_{0}=\omega_{s}$ and Equation (4), we can write $[6,18]$ the following equation:

$$
\underline{Z}=R_{1} \frac{1+j \frac{\omega_{0} L_{1}}{R_{1}}\left(\Omega-\frac{1}{\Omega}\right)}{1+\frac{C_{0}}{C_{1}}\left(1-\Omega^{2}\right)+j \frac{C_{0}}{C_{1}} \frac{R_{1}}{\omega_{0} L_{1}} \Omega}
$$

with the real part

$$
\operatorname{Re}(\underline{Z})=\frac{R_{1}}{\left[1+\frac{C_{0}}{C_{1}}\left(1-\Omega^{2}\right)\right]^{2}+\left(\frac{C_{0}}{C_{1}} \frac{R_{1}}{\omega_{0} L_{1}} \Omega\right)^{2}}
$$

and the imaginary part $[6,18]$

$$
\operatorname{Im}(\underline{Z})=-j R_{1} \frac{C_{0}}{C_{1}} \frac{\omega_{0} L_{1}}{R_{1} \Omega} \cdot \frac{\Omega^{4}-\left[2+\frac{C_{1}}{C_{0}}-\left(\frac{R_{1}}{\omega_{0} L_{1}}\right)^{2}\right] \Omega^{2}+1+\frac{C_{1}}{C_{0}}}{\left[1+\frac{C_{0}}{C_{1}}\left(1-\Omega^{2}\right)\right]^{2}+\left(\frac{C_{0}}{C_{1}} \frac{R_{1}}{\omega_{0} L_{1}} \Omega\right)^{2}}
$$


Taking into account various ways of oscillation of piezoelectric crystals, Table 1 shows values or value ranges for individual electrical equivalent circuit elements (Figure 1). For individual frequencies of crystal's oscillation, it is possible to select given values for $R_{1}, C_{1}$, and $L_{1}$.

Table 1. Element data for electrical substitute model of the piezoelectric crystal (quartz) (Figure 1) for various frequencies of oscillation (Equation (7)) [6].

\begin{tabular}{ccccc}
\hline & $f_{\mathbf{S}}$ & $\mathbf{R}_{\mathbf{1}}$ & $\mathbf{C}_{\mathbf{1}}$ & $\mathbf{L}_{\mathbf{1}}$ \\
\hline Bending vibration & $1-50 \mathrm{kHz}$ & $5-50 \mathrm{k} \Omega$ & $0.01 \mathrm{pF}$ & $10^{4}-10^{3} \mathrm{H}$ \\
\hline Longitudinal vibration & $50-200 \mathrm{kHz}$ & $2-5 \mathrm{k} \Omega$ & $0.10 \mathrm{pF}$ & $10-100 \mathrm{H}$ \\
\hline Surface vibration & $150-800 \mathrm{kHz}$ & $0.5-10 \mathrm{k} \Omega$ & $0.02 \mathrm{pF}$ & $1-10 \mathrm{H}$ \\
\hline Thickness shear vibration & $0.5-20 \mathrm{MHz}$ & $2-2000 \Omega$ & $0.01 \mathrm{pF}$ & $10-100 \mathrm{mH}$ \\
\hline
\end{tabular}

For the selected data $\mathrm{C}_{1}=3.24 \mathrm{fF}, \mathrm{L}_{1}=7281 \mathrm{H}$, and $\mathrm{R}_{1}=30 \mathrm{k} \Omega$ [6] from Table 1, a series resonance frequency $f_{\mathrm{s}}=1 /\left(2 \pi \cdot \sqrt{\left.L_{1} C_{1}\right)}=32.768 \mathrm{kHz}\right.$ can be calculated. By introducing a normalized frequency $\Omega$ (Equations (5)-(7)), the crystal's impedance change near the series resonance frequency $(32.768 \mathrm{kHz})$ can be described in Figure 2. By changing the normalized frequency $\Omega$ from 0 to $\infty$, the piezoelectric crystal impedance changes (Equations (6) and (7)) in the impedance circle (Figure 2). Place 4 (Figure 2) represents series resonant frequency $\Omega_{\mathrm{s}}$, and place 7 represents parallel resonant frequency $\Omega_{\mathrm{p}}$. In both cases, impedance imaginary parts are zero. At $\Omega_{\mathrm{S}}$ the impedance real value is very small, while at $\Omega_{\mathrm{p}}$ it is very big. Even though the real parts of impedance differ by a factor of 2500 for the resonant frequencies $\Omega_{\mathrm{s}}$ and $\Omega_{\mathrm{p}}$, the resonant frequencies differ by only $0.05 \%$. At places 6 and 8 , the absolute value of the impedance imaginary parts has the greatest value.

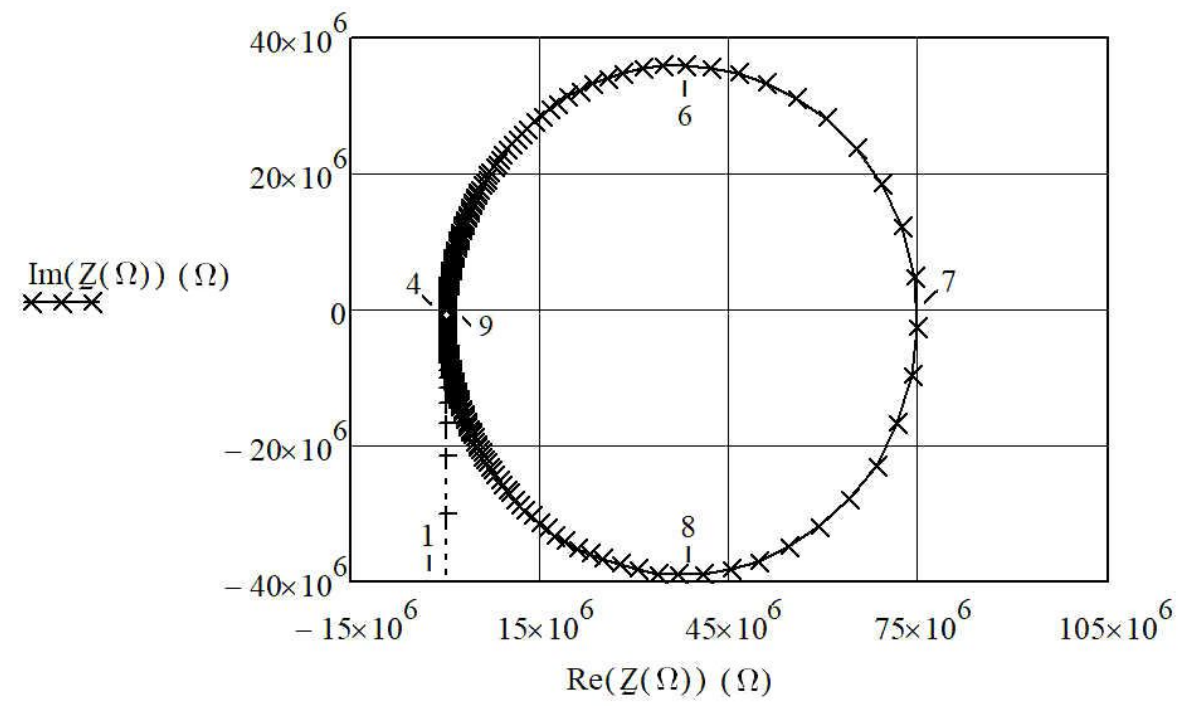

Figure 2. The complex impedance circle for the piezoelectric crystal equivalent circuit $\left(\mathrm{C}_{1}=3.24 \mathrm{fF}\right.$, $\mathrm{L}_{1}=7281 \mathrm{H}, \mathrm{R}_{1}=30 \mathrm{k} \Omega$ ). Both axes are in Ohm [22].

\section{Reactance Influence on Resonance of Piezoelectric Crystals}

Different ways of detecting physical quantities based on the change in frequency of oscillators operating with piezoelectric crystals can be demonstrated by the effect of reactance on the resonant frequency of piezoelectric crystals. Presented is the influence of reactance on the piezoelectric crystal, the way in which the capacitance lost among the crystal's electrodes is compensated, and how the mode of oscillator output frequency is converted to lower frequency range. 


\subsection{Load Capacitance Influence on Resonance}

Usually, to set the resonance frequency, the load capacitance is connected in series or in parallel with the piezoelectric crystal, depending on whether we wish to influence its series or parallel resonant frequency (Figure 3a,b) [1,3,6,21,22].
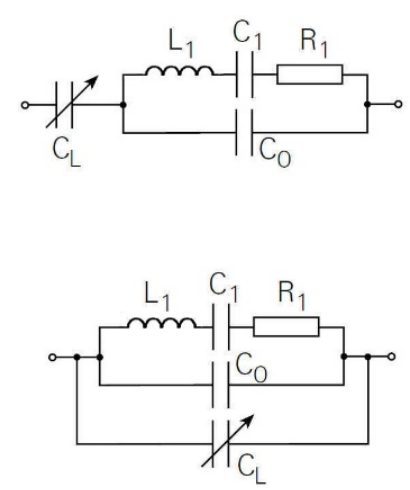

(a)

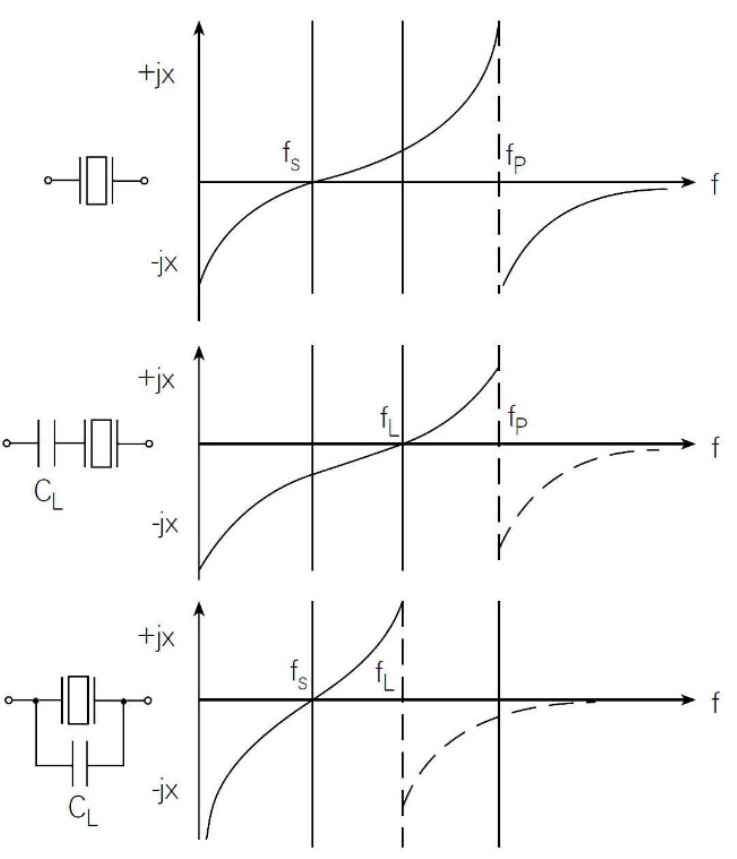

(b)

Figure 3. (a) Capacitance $C_{L}$ influence (serial and parallel) on the piezoelectric equivalent circuit; (b) The reactance curves without a load capacitance $C_{L}$, with load capacitance $C_{L}$ in series and then in parallel with piezoelectric resonator [21].

In order to calculate the influence of the series capacitance $C_{L}$ (Figure 3) on the series resonance frequency $f_{\mathrm{s}}$, the crystal resistance $\mathrm{R}_{1}$ (Equation (4)) is neglected $\left(\mathrm{R}_{1}=0\right)$, so that the series impedance is obtained for the series quartz coupling and the series capacitance $[6,18,23,24]$.

$$
\underline{Z}^{*}=\frac{j\left(\omega L_{1}-\frac{1}{\omega C_{1}}\right)}{1+\frac{C_{0}}{C_{1}}-\omega^{2} L_{1} C_{0}}+\frac{1}{j \omega C_{L}}=\frac{1}{j \omega C_{L}} \frac{C_{1}+C_{0}+C_{L}-\omega^{2} L_{1} C_{1}\left(C_{0}+C_{L}\right)}{C_{0}+C_{1}-\omega^{2} L_{1} C_{1} C_{0}}
$$

The new resonant frequency $f_{s}{ }^{*}$ for the connection in series of both elements (crystal and $C_{L}$ ) is

$$
f_{s}^{*}=\frac{1}{2 \pi \cdot \sqrt{L_{1} C_{1}}} \sqrt{1+\frac{C_{1}}{C_{0}+C_{L}}}
$$

Since in Equation (9) $C_{1} /\left(C_{0}+C_{\mathrm{L}}\right)<<1$, Equation (10) can be written as

$$
f_{\mathcal{S}}^{*} \cong \frac{1}{2 \pi \cdot \sqrt{L_{1} C_{1}}}\left(1+\frac{C_{1}}{2\left(C_{0}+C_{L}\right)}\right)
$$

The change of the series resonant frequency $\Delta f_{\mathrm{s}} / f_{\mathrm{s}}$ can be written as $[1,6]$

$$
\frac{\Delta f_{s}}{f_{s}}=\frac{\Delta \omega_{s}}{\omega_{s}}=\frac{\omega_{s}^{*}-\omega_{s}}{\omega_{s}}=\frac{C_{1}}{2\left(C_{0}+C_{L}\right)}
$$


If we know the range of capacitance $C_{L}$ change, Equation (10) can reflect the change of frequency $f_{s}^{*}$ (for example, the capacitance change $C_{L}=5-15 \mathrm{pF}$ (Figure 4)). For greater changes of capacitance $C_{L}>15 \mathrm{pF}$, the frequency change $f_{s}^{*}$ is a lot smaller.

$$
f_{s}^{*}\left(C_{L}\right)=\frac{1}{2 \pi \cdot \sqrt{L_{1} C_{1}}}\left(1+\frac{C_{1}}{2\left(C_{0}+C_{L}\right)}\right)
$$

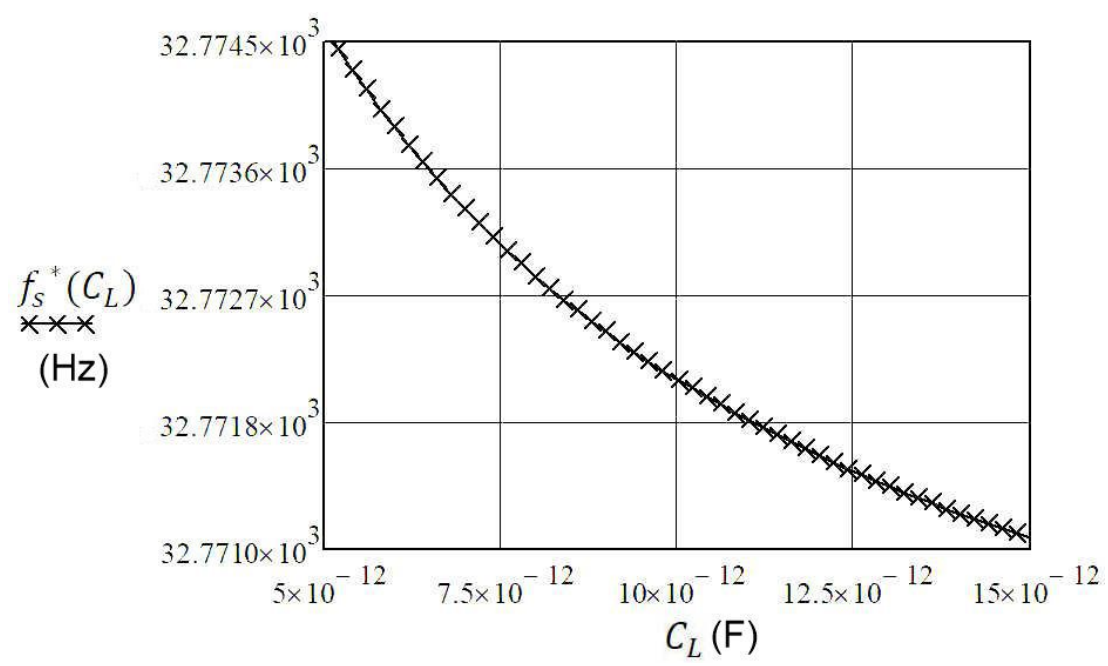

Figure 4. The range of resonant frequency changing $f_{s}^{*}=32.7710$ to $32.7745 \mathrm{kHz}$ due to the changing of capacitance $C_{L}$ in the range of $5-15 \mathrm{pF}[18,21]$.

\subsection{Capacitance Compensation of Piezoelectric Electrodes}

Capacitance $\mathrm{C}_{0}$ (Figure 1) represents the capacitance between the electrodes of the piezoelectric crystal, and can be compensated with the inductance $\mathrm{L}_{\mathrm{L}}$ in series with the crystal (Figure 5a) provided that (Equation (13)) $[6,18,20,25]$ is

$$
L_{L}=\frac{1}{\omega_{s}^{2} C_{0}}
$$

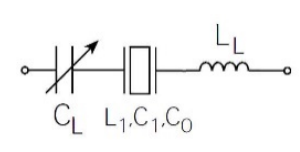

(a)

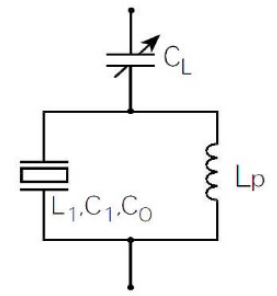

(b)

Figure 5. (a) Compensation $C_{0}$ with the inductance $L_{L}$ connected in series; (b) compensation $C_{0}$ with parallel inductance $\mathrm{L}_{\mathrm{p}}$.

If we take into account Equation (9) and Equation (13) (compensation $\mathrm{C}_{0}$ ), the new resonant frequency $\left(f_{s s}{ }^{*}\right)$ is expressed with Equation (14). With this equation, enhanced pulling sensitivity $d f_{1}$ near the series resonant frequency $f_{\mathrm{s}}$ (Equation (1)) is achieved, as shown in Figure 6.

$$
f_{S s}{ }^{*}\left(C_{L}\right) \cong \frac{1}{2 \pi \cdot \sqrt{L_{1} C_{1}}}\left(1+\frac{C_{1}}{2\left(C_{0}-\frac{1}{\omega_{s}^{2} L_{L}-\frac{1}{C_{L}}}\right)}\right)
$$




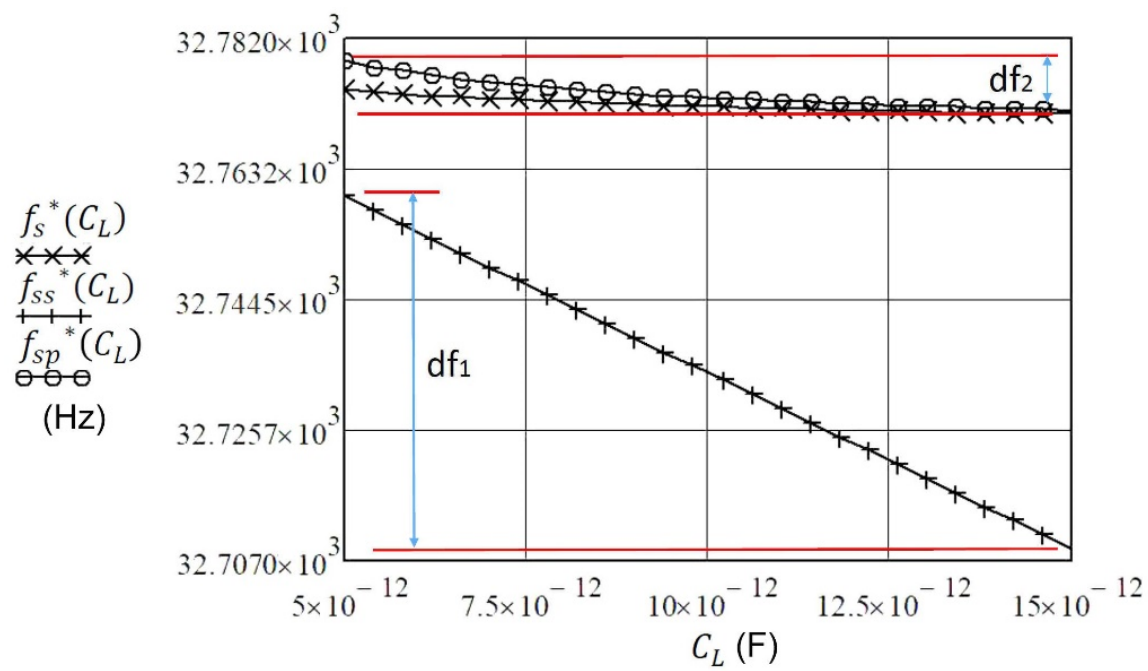

Figure 6. A comparison between the frequency changes $f_{S}{ }^{*}\left(C_{L}\right)$ (Equation (12)), frequency $f_{S S}{ }^{*}\left(C_{L}\right)$ (Equation (14)), and $f_{s p}{ }^{*}\left(C_{L}\right)$ (Equation (16)) as result of changing of capacitance $C_{\mathrm{L}}$ (in the range from od $5-15 \mathrm{pF})$.

Conversely, with high load capacitance $C_{\mathrm{L}}$ the pulling sensitivity is very small, so $100 \mathrm{pF}$ likely represents, approximately, the upper limit.

The pulling sensitivity $d f_{2}$ (Figure 6) of the crystal unit can be also increased if the $C_{0}$ is compensated by parallel inductance $L_{p}$ to the crystal (Figure $5 b$ ). The equation for compensation is

$$
\begin{gathered}
L_{p}=\frac{1}{\omega_{s}^{2} C_{0}} \\
f_{s p}{ }^{*}\left(C_{L}\right)=\frac{1}{2 \pi \cdot \sqrt{L_{1} C_{1}}} \sqrt{1+\frac{C_{1}}{C_{L}}}
\end{gathered}
$$

When $C_{L}$ is connected in series with the piezoelectric crystal (without compensation $C_{0}$ ), the frequency change $f_{s}^{*}\left(C_{L}\right)$ is the smallest in the range 5-15 pF (Figure 6). With connection $C_{L}$ in parallel and compensation $C_{0}$, the change of frequency $f_{s p}{ }^{*}\left(C_{L}\right)$ is somewhat greater but nonlinear.

With connection in series $C_{L}$ and compensation $C_{0}$, the change of frequency $f_{s s}{ }^{*}\left(C_{L}\right)$ is the greatest (the greatest frequency pulling) and linear near the resonant frequency $f_{\mathrm{s}}$. This sensitivity and linearization study is described in more detail and compared with other studies in [26].

\subsection{Load Inductance Influence on Resonance}

There is another possibility to increase the pulling sensitivity and this is to replace the series load capacitor $C_{L}$ with a series load inductance $L_{L L}$ (Figure 7) $[6,18,25]$.

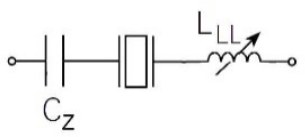

Figure 7. Load inductance $\mathrm{L}_{\mathrm{LL}}$ in series with the piezoelectric crystal.

Capacitor $C_{Z}$ (Figure 7) is intended to cancel the effective series resistance of the circuit and not to act as a load capacitor for the crystal. Capacitor $C_{Z}=\sim 10 \mathrm{nF}$ and plays the role of connecting capacitor 
that has practically no influence on the piezoelectric series resonant frequency $f_{\mathrm{s}}$, which is why in Equation (14) the expression $1 / C_{L}$ can be ignored and left out, which gives us Equation (17) [26].

$$
f_{S S S}{ }^{*}\left(L_{L L}\right) \cong \frac{1}{2 \pi \cdot \sqrt{L_{1} C_{1}}}\left(1+\frac{C_{1}}{2\left(C_{0}-\frac{1}{\omega_{S}^{2} L_{L L}}\right)}\right)
$$

If we take in account (experimental data) that $\mathrm{C}_{1}=3.24 \mathrm{fF}, \mathrm{L}_{1}=7281 \mathrm{H}, \mathrm{R}_{1}=30 \mathrm{k} \Omega$, and $f_{0}=$ $32.768 \mathrm{kHz}$ from Table 1, and that inductance $\mathrm{L}_{\mathrm{LL}}$ is changed in the range 7.1-7.5 $\mathrm{H}$ in Equation (17), we can show the frequency pulling $d f_{3}$, which is almost linear in Figure 8 and for the experimental data amounts to $8.75 \mathrm{kHz} / 5 \mathrm{mH}$. There is, however, one potential disadvantage to this method. The effective $\mathrm{Q}$ of the combination $\mathrm{L}_{1}$ and $\mathrm{L}_{\mathrm{LL}}$ (Figure 7) is dramatically reduced due to the relatively low $\mathrm{Q}$ of the inductance $\mathrm{L}_{\mathrm{LL}}$ employed. Furthermore, there is also an additionally tuned circuit created, consisting of $\mathrm{LLL}_{\mathrm{L}}, \mathrm{C}_{1}$ and $\mathrm{C}_{0}$ of the piezoelectric element.

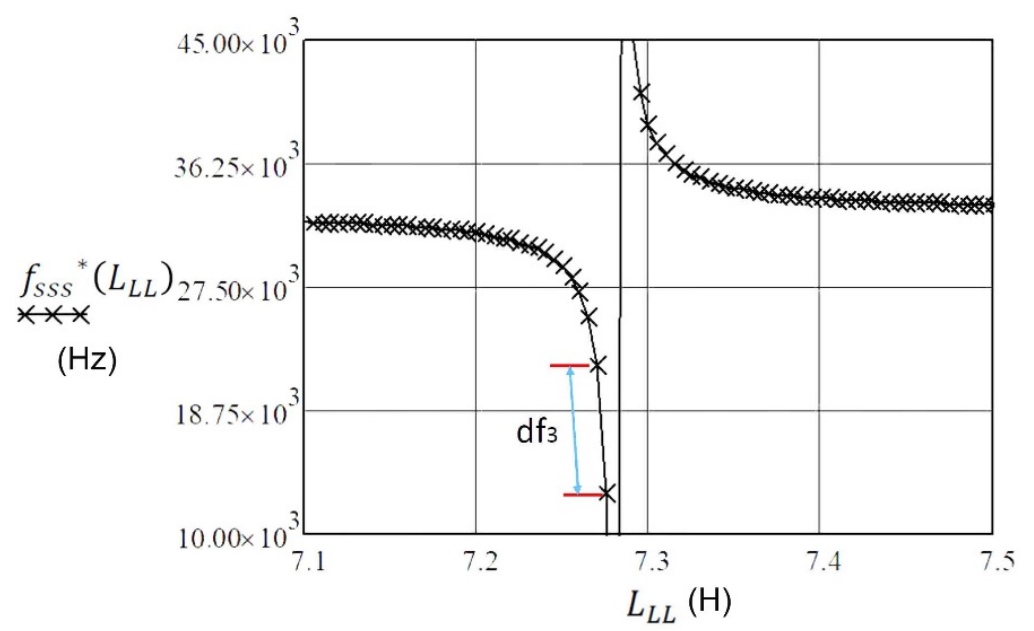

Figure 8. Inductance frequency pulling for data: $\mathrm{C}_{1}=3.24 \mathrm{fF}, \mathrm{L}_{1}=7281 \mathrm{H}, \mathrm{R}_{1}=30 \mathrm{k} \Omega, f_{0}=32.768 \mathrm{kHz}$, and for inductance $\mathrm{L}_{\mathrm{LL}}$ change in the range 7.1-7.5 $\mathrm{H}$.

All piezoelectric crystals have spurious resonances (unwanted resonance responses) beside the main resonance frequency. They are represented in the equivalent circuit by additional resonant circuits in parallel with $R_{1}, L_{1}$, and $C_{1}$ [3], and they are just other vibration modes at higher frequency values.

\subsection{Ceramic Resonators}

A cheaper alternative to the quartz crystal is a ceramic resonator. This device uses mechanical resonance of a piezoelectric ceramic, typically lead zirconate titanate, which vibrates in various

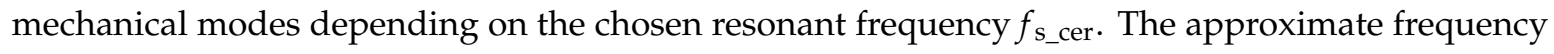
ranges are shown in Table 2 [27-30].

Table 2. Frequency ranges for various mechanical modes vibration [30].

\begin{tabular}{cc}
\hline & $f_{\text {s_cer }}$ \\
\hline Longitudinal mode & $30 \mathrm{kHz}-1 \mathrm{MHz}$ \\
\hline Area mode & $100 \mathrm{kHz}-2 \mathrm{MHz}$ \\
\hline Thickness shear mode & $1 \mathrm{MHz}-10 \mathrm{MHz}$ \\
\hline Expansion thickness mode & $2 \mathrm{MHz}-100 \mathrm{MHz}$ \\
\hline Surface wave mode & $10 \mathrm{MHz}-1 \mathrm{GHz}$ \\
\hline
\end{tabular}


The equivalent circuit of the ceramic resonator is identical to that of the quartz crystal (Figure 1), but the component values give it orders of magnitude lower $Q$. In terms of oscillation frequency accuracy, the resonator sits between the quartz crystal and the LC resonant circuit (an electric circuit consisting of an inductor, represented by the letter $\mathrm{L}$, and a capacitor, represented by the letter $\mathrm{C}$, connected together). The temperature compensation of a resonator is of the order of $10^{-5} /{ }^{\circ} \mathrm{C}$ compared to the more than $1 \mathrm{ppm} /{ }^{\circ} \mathrm{C}$ achievable with quartz, and the $10^{-3}-10^{-4} /{ }^{\circ} \mathrm{C}$ of $\mathrm{LC}$ circuits. Its initial frequency tolerance is of the order of $\pm 0.5 \%$, whereas quartz routinely achieves $\pm 0.003 \%$. To achieve these figures using LC, circuits would need a trimming adjustment. On the other hand, the resonator is cheaper and smaller than the quartz crystals and can use the same or similar oscillator circuits. An advantage of the resonator is that because of its lower $Q$, the oscillation will start up more quickly than for an equivalent crystal circuit, which makes it attractive for applications that spend a lot of their time in "sleep" mode with the oscillator powered off. All of these characteristics make the ceramic resonator the component of choice for frequency control of low- and mid-performance digital products, where a stable clock frequency is needed but where absolute accuracy or close control of temperature compensation is not a requirement. It is available in a wide range of standard frequencies (Table 2), matched to particular consumer applications [27-31].

\subsection{Oscillator Frequency Transformation Using Reference Oscillator}

Oscillator frequency measurement by frequency counter is more accurate when the frequency $f_{\text {osc }}$ of detection oscillator (Figure $9 \mathrm{a})>1 \mathrm{MHz}$ ) is transformed to lower frequency range $\left(f_{\text {out } 1}=1-100 \mathrm{kHz}\right.$ ). For this transformation, a reference oscillator and a low pass filter are used and a precise comparator circuit (or Schmitt trigger circuit) is added, which transforms a triangular signal to a rectangular signal. When using this transformation, more decimal places on the display of the frequency counter (experimentally used HM8123-X, Hameg Instruments) are accurate [1,2,31].

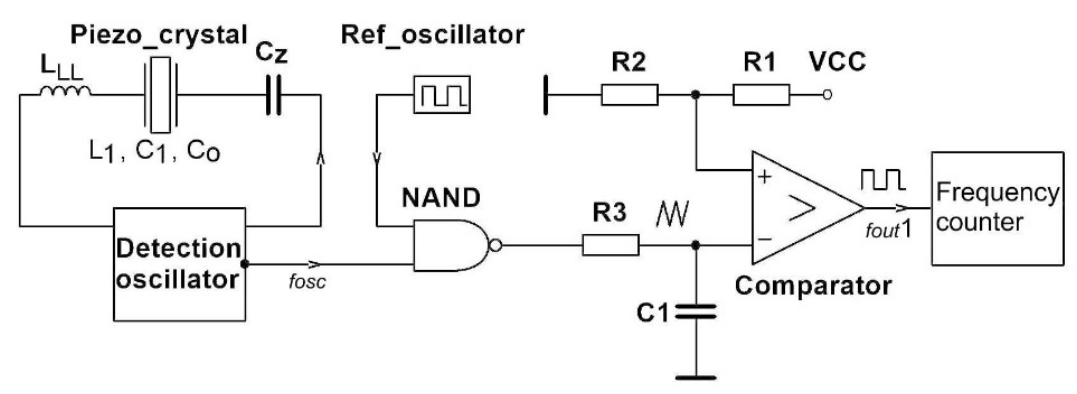

(a)

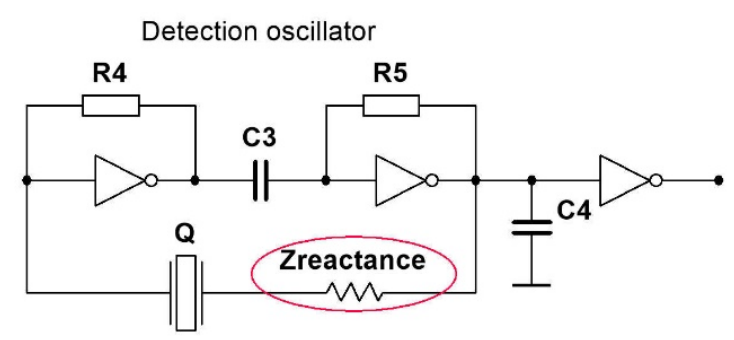

(b)

Figure 9. (a) Higher oscillator frequency $\left(f_{\text {osc }}\right)$ signal transformation to lower frequency range $\left(f_{\text {out } 1}=1-100 \mathrm{kHz}\right)$, (NAND stands for digital AND gate with negated output, VCC $=5 \mathrm{~V}$ ); (b) detection oscillator. 
The output frequency $f_{\text {out1 }}$ (Figure 9a) is defined as

$$
f_{\text {out } 1}=\left[\left(f_{\text {ref }}+d f_{\text {ref }}(T)+d f_{\text {ref }}(t)\right)-\left(f_{\text {osc }}+d f_{\text {osc }}(T)+d f_{\text {osc }}(t)\right)\right]+d f_{c_{\_} \text {error } 1}
$$

If crystal ageing $d f_{\text {osc }}(t)$ and reference oscillator crystal ageing $d f_{\text {ref }}(t)(t-$ time) are approximately the same (they compensate), we get Equation (19), where the temperature-frequency change $\left(d f_{r e f}(T), d f_{o s c}(T)\right)$ (T-temperature) is not approximately the same. In Equation (19) the frequency measurement error $d f_{c_{-} \text {error }}$ (counter error) also has to be taken into account, which includes also

$$
f_{\text {out } 1}=\left[\left(f_{\text {ref }}+d f_{\text {ref }}(T)\right)-\left(f_{\text {osc }}+d f_{\text {osc }}(T)\right)\right]+d f_{c_{-} \text {error } 1} v
$$

A piezoelectric crystal (Figure 9a) must have the temperature-frequency characteristics as much as possible independent of the temperature (AT-cut $0^{\prime}$ (the crystal's $x$ axis is inclined by $35^{\circ} 15^{\prime}$ from the $\mathrm{z}$ (optic) axis, typically operate in fundamental mode at $1-30 \mathrm{MHz}$, Figures 10 and 11) in the working temperature range of $10-40{ }^{\circ} \mathrm{C}$. The reference oscillator (Figure $9 \mathrm{a}$ ) is an oven-controlled crystal oscillator (OCXO). Experimental data were: OCT18T5, 1.25-100.0 MHz, stability 0-60 ${ }^{\circ} \mathrm{C}= \pm 0.01 \mathrm{ppm}$, ageing $\pm 0.5 \mathrm{ppm} /$ year, supply voltage variation $\pm 5 \%$. Using the method shown in Figure 9 , stability of $f_{\text {out1 }}= \pm 2 \mathrm{ppm}$ can be achieved in the temperature range of $10-40^{\circ} \mathrm{C}$ (Figure 10, cutting angle $0^{\prime}$ ) [3].

\section{Temperature-Frequency Characteristics Compensation of Piezoelectric Crystals}

With accurate detection principles using piezoelectric oscillators, the temperature stability of piezoelectric crystals is important. Different methods of temperature-frequency compensation of crystals in oscillators using temperature-frequency pairs of crystals and a procedure for compensation of the inherent temperature-frequency characteristics of crystals based on the method of switching between active and reference reactances are shown. For the latter, experimental results of the dynamic stability of the oscillator output frequency are also presented.

\subsection{Crystal Temperature Sensitivity}

Due to the crystal's physical properties, AT-cut crystals are predominantly used in oscillator circuits $[1,32]$. Their main advantage is the low temperature sensitivity in the temperature range between 10 and $40{ }^{\circ} \mathrm{C}$. The curves are represented as the cubical parabola with the temperature intersection point of $25^{\circ} \mathrm{C}$, depending on the crystal cut angle and the mechanical construction (Figure 10) [1,33,34]. Equation (18) describes the piezoelectric crystal's temperature-frequency change (in ppm) with regard to the temperature change in the range of -60 to $+110{ }^{\circ} \mathrm{C}$ (Figure 10).

$$
\frac{d f}{f}=A\left(T-T_{r e f}\right)+B\left(T-T_{r e f}\right)^{2}+C\left(T-T_{r e f}\right)^{3}
$$

where $T$ is environment temperature; $T_{\text {ref }}$ is reference temperature; and A, B, and C are coefficients determined with regard to the respective angles of the cut $[6,21,35]$.

Figure 11 demonstrates the typical synthetic crystal temperature-frequency characteristics in case of differently cut crystals [21]. The resonator plate can be cut from the source crystal in many different ways. At the CT-cut of the crystal $\left(300-900 \mathrm{kHz}\right.$, face shear, $\left.38^{\circ}\right)$ the temperature-frequency curve is a downward parabola. At the GT-cut of the crystal (0.1-3 MHz, width-extensional, $\left.51^{\circ} 7^{\prime}\right)$ the temperature coefficient between -25 to $+75^{\circ} \mathrm{C}$ is near-zero, due to cancelling effect between two modes. At the BT-cut $\left(0.5-200 \mathrm{MHz}\right.$, thickness shear, $\left.-49^{\circ} 8^{\prime}\right)$, the characteristic is similar to the AT-cut operating in b-mode (fast quasi-shear). It has well known and repeatable characteristics. DT-cut $(75-800 \mathrm{kHz}$, face shear, $\left.-52^{\circ}\right)$ is similar to CT-cut. SL-cut is $\left(-57^{\circ}\right)$ a face-shear. The temperature-frequency curve is a downward parabola. The temperature coefficient is lower than the CT-cut, where the frequency range permits. At the XY-cut (3-85 kHz, length-width flexure) the crystal is smaller than other low-frequency 
cuts, and has low impedance and low $\mathrm{C}_{0} / \mathrm{C}_{1}$ ratio. The chief application is the $32.768 \mathrm{kHz}$ crystal. NT-cut $(8-130 \mathrm{kHz})$ is length-width flexure (bending) $[6,17,35]$.

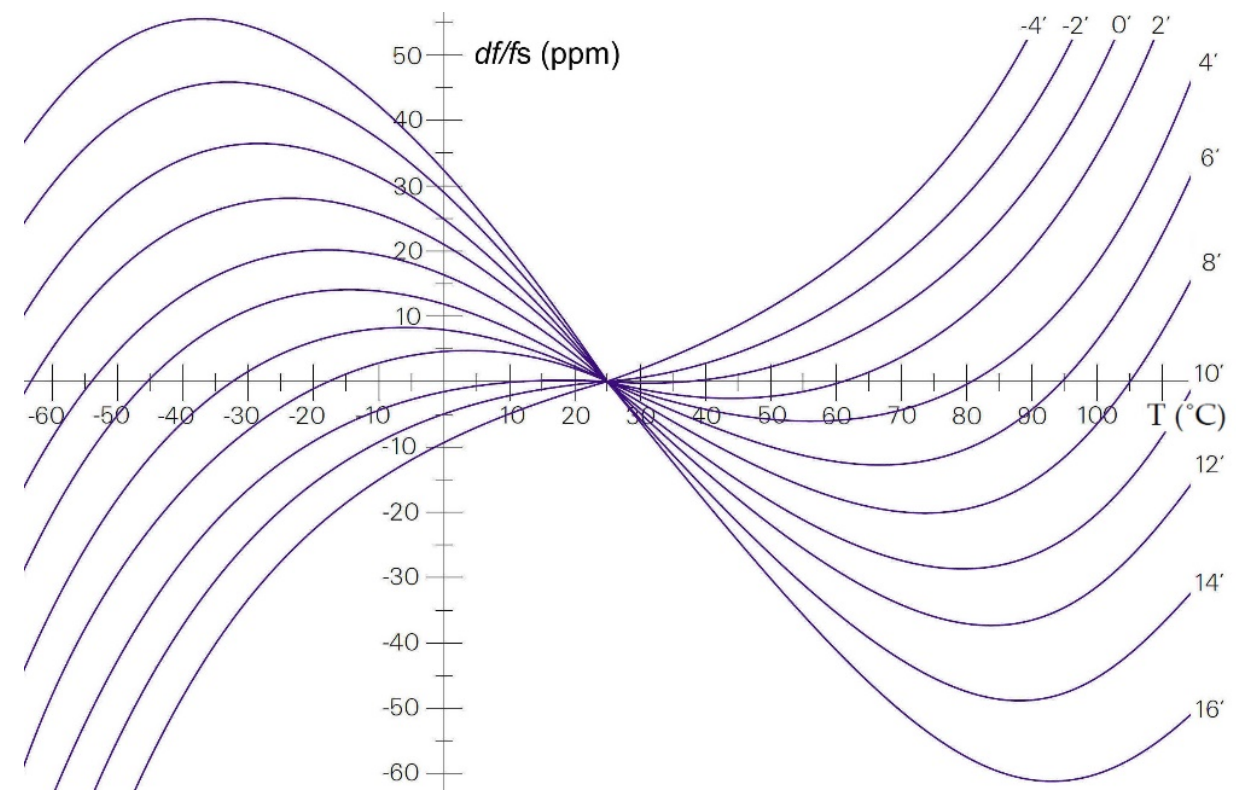

Figure 10. Temperature-frequency characteristics for thickness-shear mode AT-cut crystals with angle of cut from $-4^{\prime}$ to $+16^{\prime}$ as a parameter $[6,21,32,35]$.

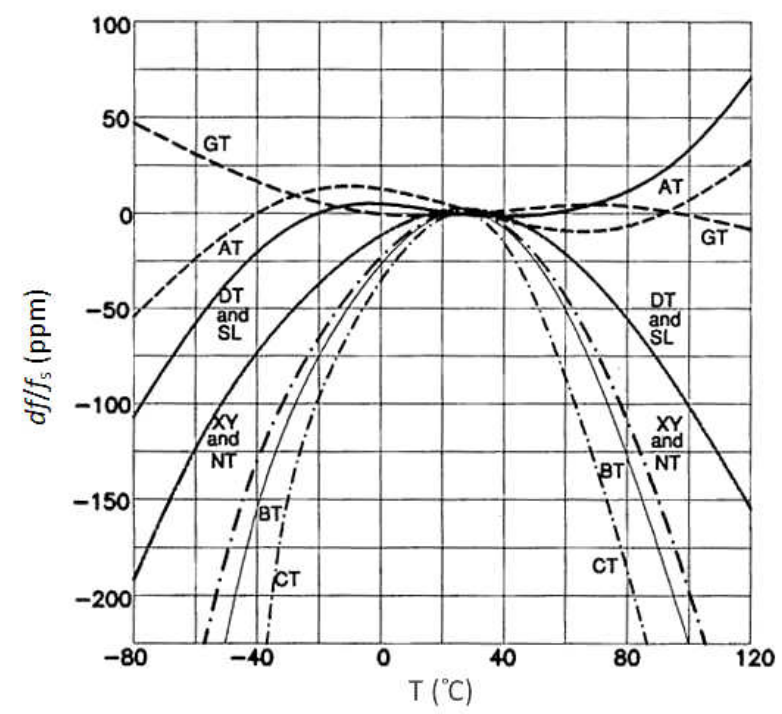

Figure 11. A temperature sensitivity of the synthetic crystals dependent on cutting angle $[6,21,32,35]$.

\subsection{Piezoelectric Crystal Temperature-Frequency Characteristics Compensation}

In case of temperature-dependent piezoelectric crystals and an external influence on the oscillating frequency with an additionally connected capacitance or inductance, the crystal oscillation cannot be temperature-compensated in the temperature range -20 to $+70{ }^{\circ} \mathrm{C}$ in the same way as it is possible to do with TCXO or OCXO oscillators that are hermetically closed in the housing. For this reason, two ways of compensation were used. In the first case, two oscillators and two crystals with approximately the same temperature characteristics (temperature pairs) were used. In the second case, one oscillator and one crystal were used, and the switching method between two impedances was employed. 


\subsubsection{Similar Crystal Temperature-Frequency Characteristics Compensation}

In the case of two crystals of similar temperature-frequency characteristics, the two oscillators and two crystals are approximately the same frequency (Figure 12) $[1,2,31,36,37]$. Impedance $Z_{\text {ref }}$ is the same as $Z_{x}$ and serves to create the same oscillating conditions in terms of impedance between the piezoelectric crystals. The frequency difference between both oscillators is $\cong 1 \mathrm{kHz}$.

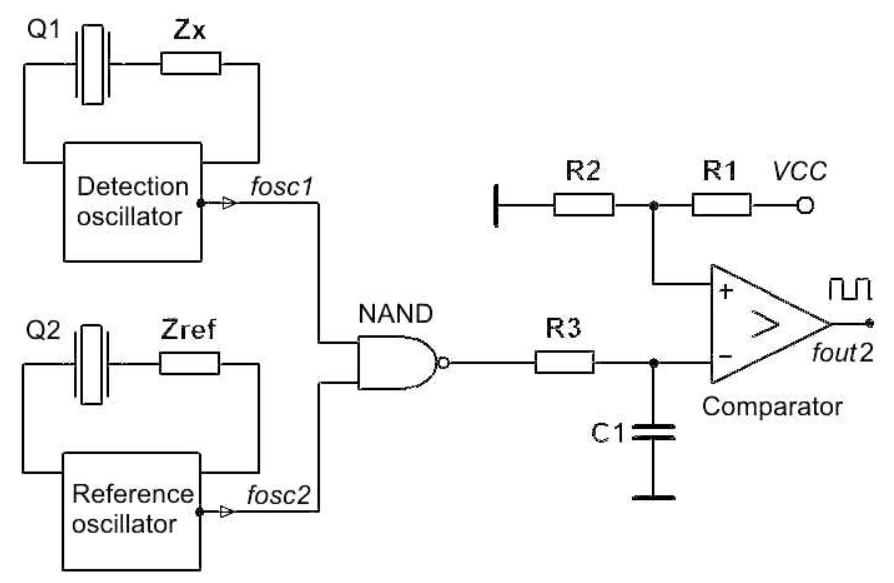

Figure 12. Detection principle by two oscillators with similar crystal temperature-frequency characteristics.

The changing of impedance $Z_{\mathrm{x}}$ triggers the change of the oscillator's frequency $f_{\mathrm{osc}}$ in the range between 1 and $100 \mathrm{kHz}$, where at the low pass filter output $\left(\mathrm{R}_{3}, \mathrm{C}_{1}\right)$ a triangular signal is created that is changed, using a comparator, into the square one that is more suitable for a frequency measurement of greater quality $[1,2,38,39]$. Equation (21) describes the output frequency $f_{\text {out2 }}$ at which the crystal ageing can be ignored, since it is the same for the two crystals, as described in Equations (18) and (19).

$$
f_{\text {out } 2}=\left[\left(f_{\text {osc } 1}+d f_{\text {osc } 1}(T)\right)-\left(f_{\text {osc } 2}+d f_{\text {osc } 2}(T)\right)\right]+d f_{c_{\_} \text {error } 2}
$$

Temperature-frequency changes $\left(d f_{o s c 1}(T)\right.$ and $\left.d f_{o s c 2}(T)\right)$ in Equation (21) are not equal, and they are not fully compensated, because the temperature-frequency characteristics of the quartzes Q1 and $\mathrm{Q} 2$ are very similar but not equal. The actual stability of the output frequency $\mathrm{f}_{\text {out } 2}$ is $\pm 1 \mathrm{ppm}$ in the temperature range $10-40{ }^{\circ} \mathrm{C}$ (Figure 10 , cutting angle $0^{\prime}$ ) [3,6].

4.2.2. Crystal's Temperature-Frequency Characteristics Compensation by Switching between the Load Capacitances

Figure 13 shows the switching method for the compensation of the crystal's own temperaturefrequency characteristics by two capacitances $\mathrm{C}_{\text {ref }}$ and $\mathrm{C}_{\mathrm{x}}$. Simultaneously, inductance $\mathrm{L}_{\text {com }}$ compensates capacitance $\mathrm{C}_{0}$ between the piezoelectric crystal electrodes, which improves the pulling sensitivity. The measurement method is based on the oscillator and the switching part of the circuit, alternatively switching reactances with the digital signal $(Q=1, \bar{Q}=0)[1,2,16,22,31,40,41]$. The output frequency $f_{\text {out3 }}$ (Equation (22) represents the output oscillator frequency, which is synchronously measured with regard to the switch of the digital signal. The switch time duration is in the range millisecond to seconds.

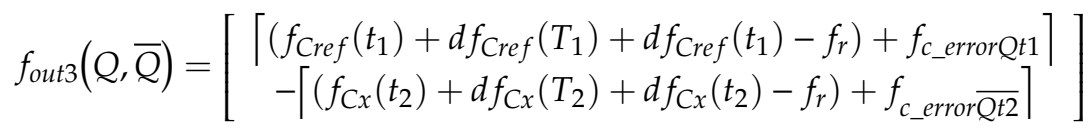

$$
\begin{aligned}
& f_{\text {out } 3}(Q, \bar{Q})=\left[\left(f_{\text {Cref }}\left(t_{1}\right)-f_{C x}\left(t_{2}\right)\right)+\left(f_{\text {C_errorQt1 } 1}-f_{\text {c_error } \overline{Q t 2}}\right)\right]
\end{aligned}
$$




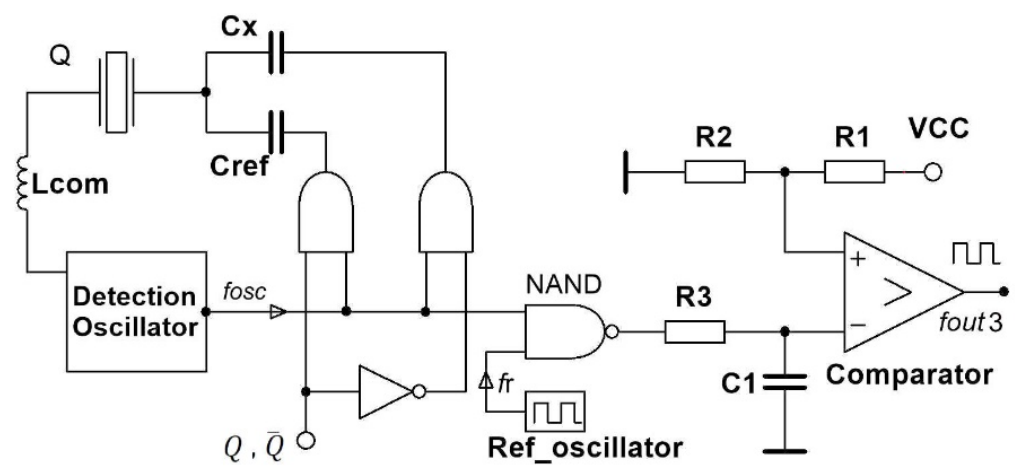

(a)

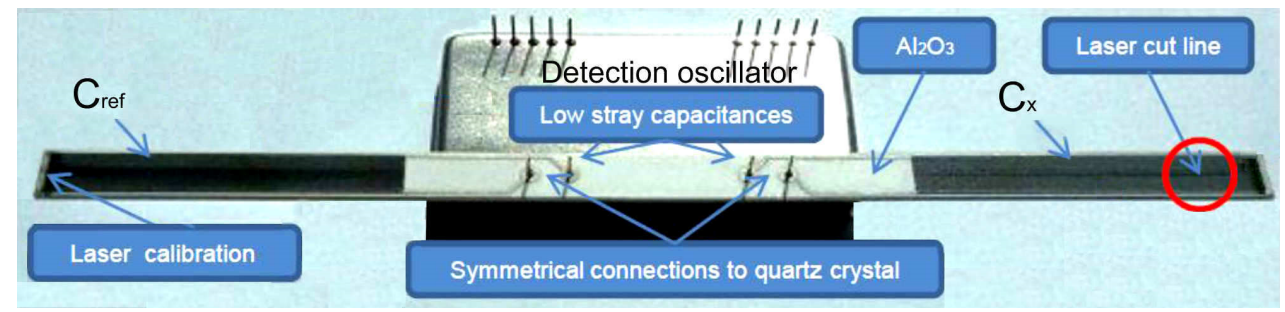

(b)

Figure 13. (a) Detection principle by one oscillator and the switching mode method compensating crystal's own temperature-frequency characteristics and crystal's electrode capacitance; (b) experimental piezoelectric detection oscillator with two equal capacitances $C_{x}$ and $C_{\text {ref }}$ and oscillator symmetrical construction [16].

When the capacitances $C_{x}$ and $C_{\text {ref }}$ are the same, $f_{\text {osc }}$ remains the same at $Q=1$ and $\bar{Q}=0$ and depends on the crystal resonant frequency $f_{\mathrm{s}}$ (Equation (1)), crystal temperature characteristics $f_{\mathrm{s}}(\mathrm{T})$, and its ageing $f_{\mathrm{s}}(\mathrm{t})$. However, when the capacitances are different, the frequency $f_{\text {osc }}$ depends on the quartz crystal resonant frequency $f_{\mathrm{s}}$, the $\mathrm{dC}_{\mathrm{x}}$ change (frequency pulling) and crystal temperature characteristics $f_{\mathrm{s}}(\mathrm{T})$, and its ageing $f_{\mathrm{s}}(\mathrm{t})$. In case of the difference of both frequencies $\mathrm{f}_{\mathrm{osc}}$ for $Q=1$ and $\bar{Q}=0, \mathrm{~d} f(\mathrm{~T})$ and $\mathrm{d} f(\mathrm{t})$ compensate because only one temperature-frequency quartz characteristic is involved. In Equation (22), the crystal's ageing $d f_{C r e f}\left(t_{1}\right)$ and $d f_{C x}\left(t_{2}\right)$ (t-time) are approximately the same and they compensate each other. Temperature-frequency changes $d f_{C r e f}\left(T_{1}\right)$ and $d f_{C x}\left(T_{2}\right)$ ( $T$ - temperature) are the same and they compensate each other when the temperature change is not so high in a short period of time up to 1 second. Reference frequency $f_{\mathrm{r}}$ from the reference oscillator is also compensated in Equation (22) by two switches, namely $Q$ and $\bar{Q}$. We get Equation (23), where the frequency measurement counter error $f_{c_{-} \text {error } Q t 1}-f_{c_{\text {e error }} \overline{\mathrm{Qt} 2}}$ is subtracted and reduced to minimum. This method highly compensates the quartz crystal's temperature-frequency characteristics. The stability of the output frequency $\mathrm{f}_{\text {out } 3}$ is $\pm 0.001 \mathrm{ppm}$ in the temperature range $10-40{ }^{\circ} \mathrm{C}$ (Figure 10 , cutting angle $\left.0^{\prime}\right)[3,16,18]$.

4.2.3. Crystal's Own Temperature-Frequency Characteristics and Simultaneous Crystal Electrode Capacitance Compensation with one Inductance

Figure 14 shows the switching mode method for the compensation of the crystal's own temperaturefrequency characteristics by two inductances, $\mathrm{L}_{\text {ref_com }}$ and $\mathrm{L}_{\mathrm{x}}$ ( $\left.\mathrm{L}_{\text {ref_com }} \cong \mathrm{L}_{\mathrm{x}}\right)[1,2,16,22,31,40,41]$. Capacitance $\mathrm{C}_{0}$ compensation between the piezoelectric crystal's electrodes is achieved by the value of $\mathrm{L}_{\mathrm{ref}}$ and $\mathrm{L}_{\mathrm{x}}$, and by the already explained Equations (13) and (14). The measurement method is similar as described in Section 4.2.2. 


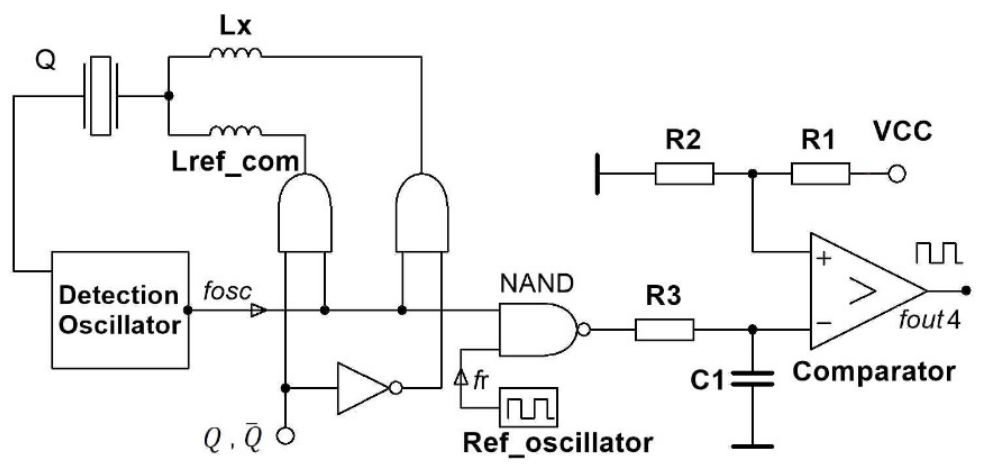

Figure 14. Detection principle by one oscillator and switching mode method compensating the crystal's temperature-frequency characteristics and the crystal's electrode capacitance by the same inductance.

The output frequency $f_{\text {out4 }}$ (Figure 14) can be written with Equation (24), in which the crystal's ageing $d f_{\text {Lref }}\left(t_{1}\right)$ and $d f_{L x}\left(t_{2}\right)$ are approximately the same and they compensate each other. Temperature-frequency changes $d f_{\text {Lref }}\left(T_{1}\right)$ and $d f_{L x}\left(T_{2}\right)$ are almost the same and they compensate each other, when the temperature change is not so high in a short period of time. Reference frequency $f_{\mathrm{r}}$ from reference oscillator is also compensated in Equation (24) by two switches, $Q, \bar{Q}$. We get Equations (25), where the frequency measurement counter error $f_{c_{-} \text {error } Q t 1}-f_{c_{-} \text {error }} \overline{Q t 2}$ is subtracted and reduced to minimum. This method highly compensates the quartz crystal's temperature-frequency characteristics.

$$
\begin{aligned}
& f_{\text {out } 4}(Q, \bar{Q})=\left[\begin{array}{c}
{\left[\left(f_{\text {Lref }}\left(t_{1}\right)+d f_{\text {Lref }}\left(T_{1}\right)+d f_{\text {Lref }}\left(t_{1}\right)-f_{r}\right)+f_{c_{\_} \text {error } Q t 1}\right]} \\
-\left\lceil\left(\left(f_{L x}\left(t_{2}\right)+d f_{L x}\left(T_{2}\right)+d f_{L x}\left(t_{2}\right)-f_{r}+f_{c_{\_} \text {error } \overline{Q t 2}}\right)\right\rceil\right.
\end{array}\right] \\
& f_{\text {out } 4}(Q, \bar{Q}, t)=\left[\left(f_{\text {Lref }}\left(t_{1}\right)-f_{L x}\left(t_{2}\right)\right)+\left(f_{c_{-} \text {error } Q t 1}-f_{c_{-} \text {error } \overline{Q t 2}}\right)\right]
\end{aligned}
$$

Figure 15 shows experimental results of the frequency stability $\left(f_{L x}\left(t_{2}\right)+d f_{L x}\left(T_{2}\right)+d f_{L x}\left(t_{2}\right)-\right.$ $f_{r}+f_{c_{-} \text {error } \overline{Q t 2}}$ ) (Equation (24) (at the beginning of temperature cycling the stable frequency $f_{\text {out } 4}(\bar{Q})$ was $1000 \mathrm{~Hz}$ at $0{ }^{\circ} \mathrm{C}$ ) occurring when the temperature is changed in the range of $0-50{ }^{\circ} \mathrm{C}$ and fixed value $\mathrm{L}_{\mathrm{x}}$ (Figure 14). The crystal used ( $5 \mathrm{MHz}$ ) in the experiment was an AT-cut (cut angle: $0^{\prime}$ ) quartz crystal with temperature change $\pm 5 \mathrm{ppm}$ in the range $10-40^{\circ} \mathrm{C}$. The $\mathrm{A}$ and $\mathrm{B}$ areas (Figure 15) illustrate dynamic change of frequency at the temperature change ranging from 0 to $50^{\circ} \mathrm{C}$ and back to $0{ }^{\circ} \mathrm{C}$.

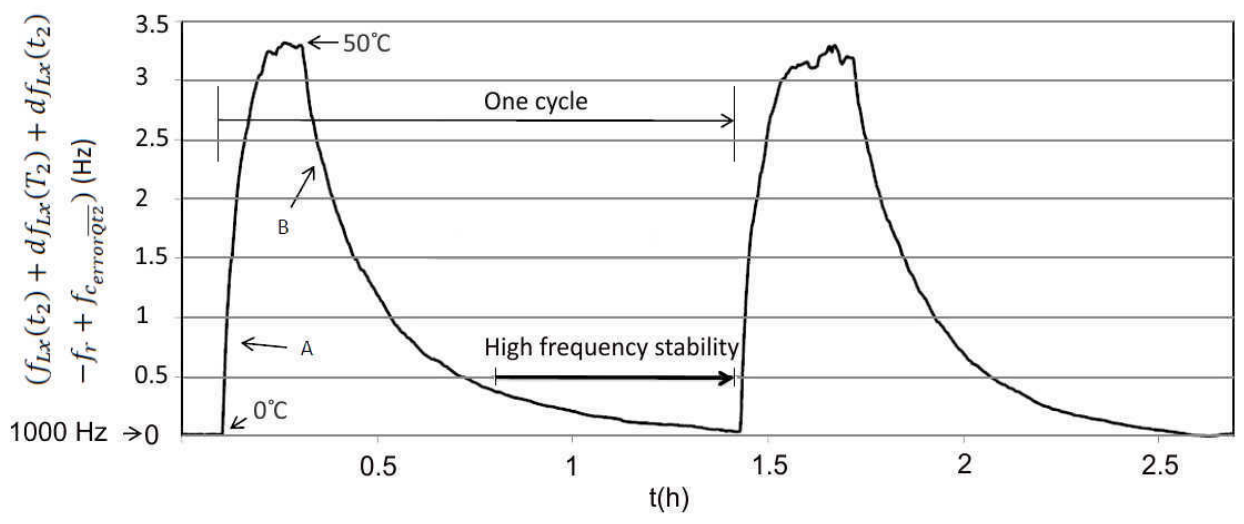

Figure 15. Frequency stability $\left(\left(f_{L x}\left(t_{2}\right)+d f_{L x}\left(T_{2}\right)+d f_{L x}\left(t_{2}\right)-f_{r}+f_{c_{-} \text {error }} \overline{\mathrm{Qt2} 2}\right)\right.$ occurring when changing the temperature in the range $0-50{ }^{\circ} \mathrm{C}$ (measurement time $2.5 \mathrm{~h}$-two cycles).

Figure 16 illustrates frequency stability $d f_{\text {out }}(Q, \bar{Q}, t)$ (Equation (25)) during the change of temperature in the range $0-50{ }^{\circ} \mathrm{C}$ at the fixed value $L_{x}$ (Figure 14) once both frequencies are deducted. Deduction of both frequencies in relation to $Q$ and $\bar{Q}$ signals is performed by LabVIEW software. 
In addition, Figure 16 also illustrates the temperature compensation of the quartz crystal natural temperature characteristics because only one characteristics of the crystal is involved.

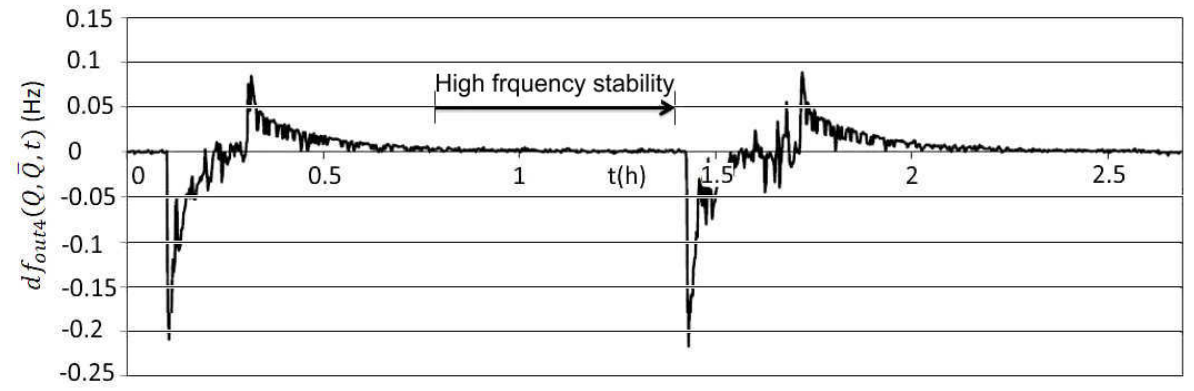

Figure 16. Frequency difference stability $d f_{\text {out } 4}(Q, \bar{Q}, t)$ at the change of temperature in the range $0-50{ }^{\circ} \mathrm{C}$, and fixed value $\mathrm{L}_{\mathrm{x}}$ (measurement time $2.5 \mathrm{~h}$-two cycles).

The comparison of results in Figures 15 and 16 points to dynamic frequency stability change (Figure 16) and to the high frequency difference stability $( \pm 0.01 \mathrm{~Hz})$ area when the temperature changes less quickly. The stability of the output frequency $f_{\text {out } 3}$ is $\pm 0.002 \mathrm{ppm}$ in the temperature range $10-40{ }^{\circ} \mathrm{C}$ (Figure 10, cutting angle $0^{\prime}$ ) [3,16,18].

\section{Discussion}

The impedance characteristics as well as series or parallel resonant frequency of the piezoelectric crystals near the resonance can be changed with reactance. The impedance conditions can be best demonstrated by introducing the norm frequency $\Omega$, where the real impedance is the smallest at series resonant frequency and the greatest at the parallel resonant frequency. The imaginary part of impedance in both cases is zero. While the serial load capacitance influences series resonant frequency, the parallel load capacitance influences the parallel resonant frequency. Based on this influence the pulling sensitivity is determined. The latter can be further enhanced by compensating the crystal's capacitance $\mathrm{C}_{0}$. The comparison of characteristics from Figure 6 shows that the pulling sensitivity is the greatest and linear $\left(\mathrm{d} f_{1}\right)$ near the piezoelectric crystal series resonance frequency at the compensation of capacitance $C_{0}$. The serial load inductance can also increase the pulling sensitivity so that we calculate the serial load inductance $\mathrm{L}_{\mathrm{LL}}$ for the compensation $\mathrm{C}_{0}$. Close to the value $\mathrm{L}_{\mathrm{LL}}$, the pulling sensitivity $\left(\mathrm{d} f_{3}\right)$ is increased when $\mathrm{L}_{\mathrm{LL}}$ is changed (Figure 8).

Since the ceramic piezo resonators have the same substitute equivalent circuits of quartz crystals, they can be treated in the similar way when they operate in the oscillating mode. Additionally, the oscillating circuits are similar or the same as in quartz crystals. Due to the lower Q-factor, they have a quicker "start-up" in oscillators.

When measuring the frequency with the help of a reference oscillator OCXO and the transformation of the signal into a square one, the measurement is more accurate. This is because the frequencies greater than $1 \mathrm{MHz}$ are transformed into the range 1-100 kHz (at lower frequencies the frequency counters measure frequency more precisely for several decimal points as they do at the frequencies higher that $1 \mathrm{MHz}$ ).

Temperature dependence of piezoelectric crystals is present in all cuts and is expressed in ppm. For a precise measurement when using oscillators and piezoelectric crystals and outside reactances, the compensation of piezoelectric crystal's own temperature-frequency characteristics is advisable. When using two oscillators (Figure 12) and temperature pair of crystals that have as similar characteristics as possible, this compensation is in the range below 1 ppm. However, when we use one oscillator, one crystal and the switching of two reactances this compensation (crystal's own temperature-frequency compensation) is approximately $0.001 \mathrm{ppm}$ [16]. This method and the results were confirmed by the experimentally produced prototype (Figure 13b). 
The factors affecting frequency stability such as wide operating temperature range, ageing and drive level, as well as all other crystal characteristics influencing the stability should also be considered because a stable oscillator circuit plays an important role in the frequency pulling sensitivity increase [32]. Frequency stability also depends on the temperature coefficient of the compensation inductance $\mathrm{L}_{\text {com }}$ and $\mathrm{L}_{\text {ref_com }}$ material. Stability of the electronic circuit depends upon the circuit type and quality of its elements. It is also important that the drive level of the quartz crystal does not exceed $5 \mu W[34]$.

\section{Conclusions}

This review presents various ways of detection with piezoelectric crystals in oscillator circuits with additionally integrated outside reactances and temperature compensations of the crystal's own temperature-frequency characteristics for measurement purposes. The review provides possible oscillator's frequency, sensitivity and linearity settings. The increased pulling range can be used for the determination of many different measurements such as low capacitance change, nano-inductance, nano-extension and compression, nano-positioning, angle, pressure, nano-force, and other non-electrical quantities.

Author Contributions: The review was carried out by V.M., who analyzed the detection principles of piezoelectric oscillators near resonance and prepared the article, while M.M. supervised the research. All authors have read and agreed to the published version of the manuscript.

Funding: The author is grateful to the Slovenian National Science Foundation for the support of this work through the project under Grant P2-7436.

Acknowledgments: The authors acknowledge the Slovenian National Science Foundation and the University of Maribor, Faculty of Electrical Engineering and Computer Science.

Conflicts of Interest: The authors declare no conflict of interest.

\section{References}

1. Euroquartz. Crystal Theory. Available online: https://euroquartz.co.uk/media/1879/tech-notes.pdf (accessed on 28 November 2019).

2. Euroquartz. Oscillator Circuits. Available online: https://www.euroquartz.co.uk/media/1878/applicationnotes.pdf (accessed on 28 November 2019).

3. Quartz Crystal Resonators and Oscillators for Frequency Control and Timing Applications. Available online: https://ieee-uffc.org/download/quartz-crystal-resonators-and-oscillators-for-frequency-control-andtiming-applications-a-tutorial-2/ (accessed on 28 November 2019).

4. Nazemi, H.; Joseph, A.; Park, J.; Emadi, A. Advanced Micro- and Nano-Gas Sensor Technology: A Review. Sensors 2019, 19, 1285. [CrossRef] [PubMed]

5. Wenjie, W.; Weihao, S.; Peter, T.; Mingsui, Y. Design and Analysis of Two Piezoelectric Cymbal Transducers with Metal Ring and Add Mass. Sensors 2019, 19, 137.

6. Schrüfer, E. Electrical Measurement: Quartz as a Frequency Reference. Carl Hanser Verlag. München Wien. 1992, 2, 405-414.

7. Valimaa, A.J.; Santos, J.T.; Ockeloen-Korppi, C.F.; Sillanpaa, M.A. Electrode configuration and electrical dissipation of mechanical energy in quartz crystal resonators. J. Micromech. Microeng. 2018, 28, 9. [CrossRef]

8. Xie, J.; Hu, Y. Electric admittance analysis of quartz crystal resonator in thickness-shear mode induced by array of surface viscoelastic micro-beams. Appl. Math. Mech. 2017, 38, 29-38. [CrossRef]

9. Li, X.; Lyu, D.; Song, Y.; Zhang, S.; Hu, P.; Jeong, H. Simultaneously Determining Sensitivity and Effective Geometrical Parameters of Ultrasonic Piezoelectric Transducers Using a Self-Reciprocity Method. IEEE Trans. Ultrason. Ferroelectr. Freq. Control 2019, 66, 1649-1657. [CrossRef]

10. Xu, T.; Zhao, L.; Jiang, Z.; Guo, S.; Li, Z.; Luo, G.; Sun, L.; Zhang, L. An Analytical Equivalent Circuit Model for Optimization Design of a Broadband Piezoelectric Micromachined Ultrasonic Transducer with an Annular Diaphragm. IEEE Trans. Ultrason. Ferroelectr. Freq. Control 2019, 66, 1760-1776. [CrossRef]

11. Qin, T.; Zjajo, A.; Berkelaarand, M.; van der Meijs, N. Considering Crosstalk Effects in Statistical Timing Analysis. IEEE Trans. Comput.-Aided Des. Integr. Circuits Syst. 2014, 33, 318-322. 
12. Altammar, H.; Dhingra, A.; Salowitz, N. Initial study of internally embedded shear-mode piezoelectric transducers for the detection of joint defects in laminate structures. J. Intell. Mater. Syst. Struct. 2019, 30, 2314-2330. [CrossRef]

13. Houguang, L.; Jinlei, C.; Jianhua, Y.; Zhushi, R.; Gang, C.; Shanguo, Y.; Xinsheng, H.; Mengli, W. Concept and Evaluation of a New Piezoelectric Transducer for an Implantable Middle Ear Hearing Device. Sensors 2017, 17, 2515.

14. Saifullah, A.; Ronan, Z.; Bram, N. A Self-Oscillating Boosting Amplifier with Adaptive Soft Switching Control for Piezoelectric Transducers. IEEE J. Solid State Circuits 2019, 54, 253-265.

15. Bandey, H.L.; Martin, S.J.; Cernosek, R.W.; Hillman, A.R. Modeling the Responses of Thichness-Shear Mode Resonators under Various Loading Conditions. Anal. Chem. 1999, 71, 2205-2214. [CrossRef] [PubMed]

16. Matko, V. Next generation AT-cut quartz crystal sensing devices. Sensors 2011, 11, 4474-4482. [CrossRef] [PubMed]

17. Vivek, R.T. A Review of Electric Impedance Matching Techniques for Piezoelectric Sensors, Actuators and Transducers. Electronics 2019, 8, 169.

18. Statek. The Quartz Crystal Model and Its Frequencies. Technical Note 32. Available online: http: //statek.com/wp-content/uploads/2018/03/tn32.pdf (accessed on 16 December 2019).

19. Min-Chiang, C.; Zi-Neng, H.; Shih-Yung, P.; Wang, Z.; Lam, C.S. Modified BVD-Equivalent Circuit of FBAR by Taking Electrodes into Account; IEEE: Piscataway, NJ, USA, 2002; Volume 1, p. 973.

20. Stanford. QCM100-Quartz Microbalance Theory and Calibration. Available online: http://www.thinksrs. com/downloads/PDFs/ApplicationNotes/QCMTheoryapp.pdf (accessed on 16 December 2019).

21. Jauch. Quartz Crystal Theory. Measurement Methods. Pulling Sensitivity. Available online: https://www. jauch.com/downloadfile/5804d138f41b5_c3e35434e616a6a82bd5/quartz_crystal_theory_2007.pdf (accessed on 19 December 2019).

22. Shuyu, L.; Jie, X. Effect of the Matching Circuit on the Electromechanical Characteristics of Sandwiched Piezoelectric Transducers. Sensors 2017, 17, 329.

23. Na, W.S.; Beak, J. A Review of the Piezoelectric Electromechanical Impedance Based Structural Health Monitoring Technique for Engineering Structures. Sensors 2018, 18, 1307. [CrossRef]

24. Budoya, D.; Bruno de, C.; Leandro, C.; Ricardo da, S.; Everaldo de, F.; Fabricio, B. Analysis of Piezoelectric Diaphragms in Impedance-Based Damage Detection in Large Structures. Proceedings 2017, 2, 131. [CrossRef]

25. Matko, V. A Comparison of Frequency Pullability in Oscillators Using a Single AT-Cut Quartz Crystal and Those Using Two Single AT- Cut Crystals Connected in Parallel with a Series Load Capacitance or Series Load Inductance. Sensors 2006, 6, 746-755. [CrossRef]

26. Matko, V.; Safaric, R. Major Improvements of Quartz Crystal Pulling Sensitivity and Linearity Using Series Reactance. Sensors 2009, 9, 8263-8270. [CrossRef]

27. Erhart, J.; Sebastian, T. Effective Electromechanical Coupling for the Partially Electroded Ceramic Resonators of Different Geometries. Ann. Univ. Dunarea De Jos Galati: Fascicle Ixmetallurgy Mater. Sci. 2015, 33, 7-16.

28. Karlash, V. Influence of Electric Loading Conditions on the Vibrations of Piezoceramic Resonators. Int. Appl. Mech. 2017, 53, 220. [CrossRef]

29. Zaitsev, B.D.; Semyonov, A.P.; Teplykh, A.A.; Borodina, I.A. The sensor for measuring the micro-displacements based on the piezoelectric resonator with lateral electric field. Ultrasonics 2019, 99, 105973. [CrossRef]

30. Williams, P. The Circuit Designer's Companion, 4th ed.; Newnes: Amsterdam, The Netherlands, 2017; pp. 151-157.

31. Arnau, A. A Review of Interface Electronic Systems for AT-cut Quartz Crystal Microbalance Applications in Liquids. Sensors 2008, 8, 370-411. [CrossRef] [PubMed]

32. Walls, F.L.; Vig, J.R. Fundamental limits on the frequency stabilities of crystal oscillators. IEEE Trans. Ultrason. Ferroelectr. Freq. Control 1995, 42, 576. [CrossRef]

33. Kusters, J.A.; Vig, J.R. Thermal hysteresis in quartz resonators-A review (frequency standards). In Proceedings of the 44th Annual Symposium on Frequency Control, Baltimore, MD, USA, 23-25 May 1990; pp. 165-175.

34. Vig, J.R.; Filler, R.L. Temperature stable crystal oscillator. IEEE Trans. Ultrason. Ferroelectr. Freq. Control 1995, 42, 797. [CrossRef]

35. Digital_Electronic_Siegfried. Quartz Crystals. Introduction and Guidance. Available online: https: //www.digitallehrer.de/technische-einfuehrung-116179.html?language=en (accessed on 9 December 2019). 
36. Shao, J.; Yan, Z.; Han, S.; Li, H.; Gao, T.; Hu, X.; Wei, C. Differential signal extraction for continuous wave mud pulse telemetry. J. Pet. Sci. Eng. 2017, 148, 127-130. [CrossRef]

37. Chen, C.; Yang, W.; Wang, J.; Lu, W.; Liu, X.; Jiang, X. Accurate and efficient height extraction in chromatic confocal microscopy using corrected fitting of the differential signal. Precis. Eng. 2019, 56, 447-454. [CrossRef]

38. Bowick, C.; Ajluni, C.J.; Blyler, J. RF Circuit Design; Newnes: Amsterdam, The Netherlands, 2008; pp. 1-167.

39. Bhattacharjee, S.; Sikder, N.; Singh, K.M. Ultrasonic Vibration Measurement based on FM demodulation in PLL Technique. In Proceedings of the 2019 2nd International Conference on Innovations in Electronics, Signal Processing and Communication (IESC), Shillong, India, 1-2 March 2019; pp. 232-237.

40. Bradley, D.; Fear, M.; Fisher, S.; Guénault, A.; Haley, R.; Lawson, C.; Pickett, G.; Schanen, R.; Tsepelin, V.; Wheatland, L. Hysteresis, Switching and Anomalous Behaviour of a Quartz Tuning Fork in Superfluid He. J. Low Temp. Phys. 2014, 175, 379-384. [CrossRef]

41. Galagedera, S.K.K.; Flechsig, G.U. Deuterium Isotope Effects Upon the Redox-switching of the Viscosity of DNA Layers Observed by Electrochemical Quartz Crystal Micro-balance. Electroanalysis 2019, 31, 2074-2080. [CrossRef]

(C) 2020 by the authors. Licensee MDPI, Basel, Switzerland. This article is an open access article distributed under the terms and conditions of the Creative Commons Attribution (CC BY) license (http://creativecommons.org/licenses/by/4.0/). 